\title{
Chronic Enhancement of the Intrinsic Growth Capacity of Sensory Neurons Combined with the Degradation of Inhibitory Proteoglycans Allows Functional Regeneration of Sensory Axons through the Dorsal Root Entry Zone in the Mammalian Spinal Cord
}

\author{
Michael P. Steinmetz, ${ }^{1}$ Kevin P. Horn, ${ }^{3}$ Veronica J. Tom, ${ }^{3,4}$ Jared H. Miller, ${ }^{3 \dagger}$ Sarah A. Busch, ${ }^{3}$ Dileep Nair, ${ }^{2}$ \\ Daniel J. Silver, ${ }^{3}$ and Jerry Silver ${ }^{1,3}$ \\ Departments of ${ }^{1}$ Neurosurgery and ${ }^{2}$ Neurology, The Cleveland Clinic Foundation, Cleveland, Ohio 44195, ${ }^{3}$ Department of Neurosciences, Case Western \\ Reserve University, Cleveland, Ohio 44106, and 4Department of Neurobiology and Anatomy, Drexel University, Philadelphia, Pennsylvania 19104
}

Peripherally conditioned sensory neurons have an increased capacity to regenerate their central processes. However, even conditioned axons struggle in the presence of a hostile CNS environment. We hypothesized that combining an aggressive conditioning strategy with modification of inhibitory reactive astroglial-associated extracellular matrix could enhance regeneration. We screened potential treatments using a model of the dorsal root entry zone (DREZ). In this assay, a gradient of inhibitory chondroitin sulfate proteoglycans (CSPGs) stimulates formation of dystrophic end bulbs on adult sensory axons, which mimics regeneration failure in vivo. Combining inflammation-induced preconditioning of dorsal root ganglia in vivo before harvest, with chondroitinase $\mathrm{ABC}$ (ChABC) digestion of proteoglycans in vitro allows for significant regeneration across a once potently inhibitory substrate. We then assessed regeneration through the DREZ after root crush in adult rats receiving the combination treatment, ChABC, or zymosan pretreatment alone or no treatment. Regeneration was never observed in untreated animals, and only minimal regeneration occurred in the ChABC- and zymosanalone groups. However, remarkable regeneration was observed in a majority of animals that received the combination treatment. Regenerated fibers established functional synapses, as demonstrated electrophysiologically by the presence of an H-reflex. Two different postlesion treatment paradigms in which the timing of both zymosan and ChABC administration were varied after injury were ineffective in promoting regeneration. Therefore, zymosan pretreatment, but not posttreatment, of the sensory ganglia, combined with ChABC modification of CSPGs, resulted in robust and functional regeneration of sensory axons through the DREZ after root injury.

Key words: proteoglycan; inflammation; H-reflex; regeneration; conditioning lesion; spinal cord; glial scar

\section{Introduction}

Several factors contribute to regeneration failure in the injured CNS. Inhibitory chondroitin sulfate proteoglycans (CSPGs) in the forming scar (McKeon et al., 1995; Pasterkamp et al., 1999; Bundesen et al., 2003; Jones et al., 2003; Goldshmit et al., 2004; Silver and Miller 2004) and throughout the perineuronal net (Lander et al., 1998; Berardi et al., 2004; Miyata et al., 2004),

\footnotetext{
Received May 25, 2005; revised July 20, 2005; accepted July 21, 2005.

We thank the Danny Heumann Fund for Spinal Cord Research, the Brumagin Memorial Fund, The American Association of Neurological Surgeons, The Cloward Fellowship Program, National Institutes of Health (Training Grant T32 AG00271), and National Institute of Neurological Disorders and Stroke (Grant NS25713 to J.S.) for supporting this research. We also extend our thanks to Alicia Yonkof for her careful review of this manuscript and to Catherine Doller for technical assistance. Sadly, our young colleague, Jared H. Miller, recently passed away, and we dedicate our paper to his everlasting memory.

'Deceased, June 29, 2005

Correspondence should be addressed to Dr. Jerry Silver, Department of Neurosciences, Case Western Reserve University, Cleveland, 0H 44106. E-mail: jxs10@cwru.edu.

D01:10.1523/JNEUROSCI.2111-05.2005

Copyright $\odot 2005$ Society for Neuroscience $\quad$ 0270-6474/05/258066-11\$15.00/0
}

growth cone collapsing myelin products (Schnell and Schwab, 1993; Cai et al.; 2001; Wang et al., 2002), and a lack of environmental trophic (Tuszynski, 1999; Jin et al., 2002) or tropic (Grimpe et al., 2002) support all negatively impact axonal regrowth. Furthermore, adult neurons decline in their intrinsic ability to elaborate axons (Goldberg et al., 2002; Verma et al., 2005). To permit effective axonal regeneration, it is likely that all of these barriers will have to be overcome in concert.

Indeed, growing evidence suggests that stimulation of the inherent capacity for axonal elongation needs to be coupled with a method for decreasing critical extrinsic barriers, or the ability of axons to respond to them, to generate more optimal regeneration. Thus, Tropea et al. (2003) demonstrated that the regeneration potential of retinal ganglion cell axons in the tectum can be enhanced by combining intraocular neurotrophic support with chondroitinase ABC (ChABC) modification of inhibitory CSPGs within the midbrain perineuronal net. Reducing Nogo signaling (Fischer et al., 2004a) or inactivating RhoA (Fischer et al., 2004b) 
combined with inflammation-induced stimulation of the intrinsic growth program of the retinal ganglion cells significantly promoted regeneration of axons in the crushed optic nerve. In the lesioned spinal cord, augmenting cAMP levels (Qiu et al., 2002; Pearse et al., 2004), locally increasing neurotrophin levels distal to the lesion (Lu et al., 2004), or modifying the scar with ChABC (Fouad et al., 2005) together with the use of growth-promoting ensheathing glia (Fouad et al., 2005), Schwann cells (Pearse et al., 2004), or bone marrow-derived stromal cells to bridge the lesion (Lu et al., 2004) allows for axonal regrowth past the site of injury. The critical task that remains is to integrate strategies that work effectively in each of the many animal models of regeneration failure in hopes of applying them to the treatment of human CNS injury.

Previously, we developed an in vitro model of the glial scar in which CSPGs distributed in a gradient produce classic retraction end bulbs on adult sensory axons (Tom et al., 2004a; Kerschensteiner et al., 2005). In the present study, we found that an intense, inflammation-induced preconditioning of the sensory neurons triggered by zymosan injection into the DRG (Fitch et al., 1999) coupled with in vitro ChABC digestion of the aggrecan substrate, results in substantial axon regeneration across the harsh environment of the gradient. We further show that the same treatment regimen results in anatomically dramatic and functionally effective sensory axon regeneration through the dorsal root entry zone (DREZ) in the adult rat. However, in this model of regeneration, lengthy preconditioning of the sensory neurons is critical.

\section{Materials and Methods}

\section{In vitro analysis of neuronal process growth potential}

Proteoglycan spot assay. Aggrecan/laminin spot gradient coverslips were prepared as described previously (Tom et al., 2004a). Briefly, glass coverslips coated with poly-L-lysine and nitrocellulose were spotted with $2 \mu \mathrm{l}$ of a solution of aggrecan $(0.7 \mathrm{mg} / \mathrm{ml}$; Sigma, St. Louis, MO) and laminin ( $5 \mu \mathrm{g} / \mathrm{ml}$; Biomedical Technologies, Stoughton, MA) in calcium and magnesium-free HBSS (CMF) (Invitrogen, Gaithersburg, MD). The spots were allowed to air dry, and then the coverslips were coated with laminin $(5 \mu \mathrm{g} / \mathrm{ml})$ in $\mathrm{CMF}$ and kept at $37^{\circ} \mathrm{C}$ for $3 \mathrm{~h}$. Before DRG culture initiation, the laminin/CMF solution was removed. ChABC-treated coverslips were incubated in ChABC $(0.5 \mathrm{U} / \mathrm{ml}$; Seikagaku, Tokyo, Japan $)$ in CMF for $3 \mathrm{~h}$. The coverslips were washed once with Neurobasal-A (Invitrogen) before DRG culture initiation.

$D R G$ dissociation. Adult DRGs were isolated according to a previous protocol (Davies et al., 1997). Single-cell suspensions of DRG neurons were prepared from adult female Sprague Dawley rats (Zivic-Miller Laboratories, Zelienople, PA). The lumbar level 4 (L4), L5, and L6 DRGs were removed bilaterally and dissected free of rootlets and capsule. Suspensions were incubated in dispase/collagenase in CMF. Adult DRG neurons were rinsed several times in CMF with gentle trituration producing a single-cell suspension. After several low-speed spins, neurons were resuspended in Neurobasal-A/B27 (Invitrogen) and incubated on spot assay coverslips (2000 cells per coverslip), treated with and without $\mathrm{ChABC}$, at $37^{\circ} \mathrm{C}\left(5 \% \mathrm{CO}_{2}, 95 \%\right.$ humidity $)$ for $5 \mathrm{~d}$.

In vivo preconditioned DRG cultures. Adult female Sprague Dawley rats (275-300 g) were anesthetized by intraperitoneal injection of ketamine (100 mg/kg; Fort Dodge Animal Health, Fort Dodge, IA) and xylazine ( $2.4 \mathrm{mg} / \mathrm{kg}$; Lloyd Laboratories, Shenandoah, IA). The L4, L5, and L6 DRGs were fully exposed bilaterally, and $1 \mu \mathrm{l}$ of saline, latex microspheres (a particulate concentration similar to zymosan; $3 \mu \mathrm{m}$; Polysciences, Warrington, PA), dibutyryl cAMP (db-cAMP) (50 mM; Sigma), and zymosan $(31 \mu \mathrm{g} / \mu \mathrm{l}$; Molecular Probes, Eugene, OR) was injected into the left DRGs (all groups, $n=8$ animals). The injection was performed via a $5 \mu \mathrm{l}$ Hamilton syringe mounted on a Brinkman Instruments (Westbury, NY) Micromanipulator. The right-side DRGs served as untreated controls. After the microinjections, the muscle was closed in lay- ers with 4-0 suture, and the skin was closed with staples. The rats were kept warm until recovery from anesthesia. All animals received an intramuscular injection of penicillin-G immediately after surgery.

Additional animals $(n=8)$ underwent conditioning lesions of the sciatic nerve. Adult female Sprague Dawley rats (275-300 g) were anesthetized as detailed above. A left thigh incision fully exposed the left sciatic nerve, proximal to the tibial/peroneal division. The exposed nerve was crushed twice using jeweler's forceps for $10 \mathrm{~s}$ each. The muscle was then closed in layers using 4-0 sutures, and the skin was secured with staples. After 2 or $7 \mathrm{~d}$, animals were killed, and the right (unconditioned) and left (conditioned) L4, L5, and L6 DRGs were removed and dissociated as detailed above. Single-cell suspensions (2000 cells per coverslip) in Neurobasal-A/B27 were cultured on the spot assay and allowed to incubate at $37^{\circ} \mathrm{C}\left(5 \% \mathrm{CO}_{2}, 95 \%\right.$ humidity) for $5 \mathrm{~d}$.

In vitro stimulation assay. Adult female Sprague Dawley rats (275-300 g) were killed via inhaled isofluorane (Baxter, Deerfield, IL). DRGs were removed and dissociated as described above. Single-cell suspensions (2000 cells per coverslip) in Neurobasal-A/B27 were plated on the spot assay and allowed to incubate at $37^{\circ} \mathrm{C}\left(5 \% \mathrm{CO}_{2}, 95 \%\right.$ humidity) for $5 \mathrm{~d}$ with one of the following: $100 \mu \mathrm{M}$ 3-isobutyl-1-methylxanthine (IBMX) (Sigma), $200 \mu \mathrm{M}$ Rolipram (Sigma), $1 \mathrm{~mm}$ db-cAMP, $1 \mathrm{~mm}$ 8-bromocGMP (8-Br-cGMP) (Sigma), $50 \mathrm{ng} / \mathrm{ml}$ nerve growth factor (NGF) (Austral Biologicals, San Ramon, CA), $50 \mathrm{ng} / \mathrm{ml}$ neurotrophin-3 (NT-3)

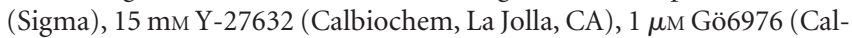
biochem), or $31 \mu \mathrm{g} / \mu \mathrm{l}$ zymosan.

Immunohistochemistry. After $5 \mathrm{~d}$ of culture in all conditions, coverslips were fixed in $4 \%$ paraformaldehyde (PFA), then washed in PBS, and blocked with $5 \%$ normal goat serum (Invitrogen), $0.1 \%$ bovine serum albumin (Sigma) with or without $0.1 \%$ Triton X-100 (Sigma) when appropriate. The coverslips were incubated overnight in primary antibody diluted in blocking solution, followed by appropriate secondary antibodies in blocking solution according to standard immunofluorescent methods. Monoclonal primary antibodies included anti $\beta$-tubulin-type III (1:400; Sigma), anti-S-100 (1:200; Sigma), anti-chondroitin sulfate (CS56; 1:200; Sigma), anti-2-B-6 (1:200; Seikagaku, Rockville, MD), and ED-1 (1:250; Chemicon). Secondary antibodies used were conjugated to Alexa 594 or 488 (1:500; Molecular Probes). Coverslips were examined using a Leitz (Wetzlar, Germany) Orthoplan-2 fluorescence microscope.

\section{Quantification of in vitro analyses}

Axon crossing of the spot rim. Six representative digital images of spot rims immunostained for CS-56 and $\beta$-tubulin III were collected with a $10 \times$ objective. Each image was standardized to include an exact proportion of area inside and outside of the spot rim using a template. The outer rim of the spot was identified, and an inner rim boundary was added at a predetermined distance from the outer rim, creating equal width rims on all images. All neuronal growth on either side of this rim was eliminated using Photoshop (Adobe Systems, San Jose, CA). Therefore, only growth within or through the rim of the spot was quantified. To eliminate background, the pixel area in each image above a set threshold was quantified (MetaMorph; Universal Imaging Corporation, West Chester, PA) representing neuronal process growth. Average threshold pixel densities were calculated per each treatment group and compared using one-way ANOVA, followed by Bonferroni's method of post hoc analysis.

Satellite glia. Coverslips were stained with S-100 to identify satellite glia/Schwann cells. The glia were quantified in the rim of the spot using the protocol described above. Average threshold pixel densities were calculated per each treatment group and compared using one-way ANOVA, followed by Tukey's method of post hoc analysis.

\section{In vivo dorsal root entry zone model}

Zymosan injection. Adult female Sprague Dawley rats (275-300 g; $n=8$ for zymosan pretreatment group and $n=12$ for combination treatment group) (supplemental Table 1, available at www.jneurosci.org as supplemental material) were anesthetized as detailed above. Under aseptic technique, the cervical level 8 (C8) DRG and associated dorsal root were fully exposed. One microliter of zymosan $(31 \mu \mathrm{g} / \mu \mathrm{l})$ was injected into the DRG via a $5 \mu$ l Hamilton syringe. We chose to use this particular ganglion for in vivo study because of its ease of identification, large size, and 
relatively short root. Care was taken to avoid excess trauma to the DRG. The injection was performed over $15 \mathrm{~min}$, and the needle was left in place an additional $3 \mathrm{~min}$ before removal. The muscle was closed in layers, and the skin was closed with staples. Animals received an intramuscular injection of penicillin-G (600,000 U/ml; Monarch Pharmaceuticals, Bristol, TN) immediately after surgery and were given analgesics in their water. Animals received zymosan injections either $7 \mathrm{~d}$ before lesion or at predetermined times after lesion (see below).

Root injury and ChABC injection. Adult rats $(n=12)$ in the ChABC treatment group (supplemental Table 1, available at www.jneurosci.org as supplemental material) were anesthetized as above. In the combination treatment group, $7 \mathrm{~d}$ after zymosan injections, animals $(n=12)$ were reanesthetized as detailed above. Under aseptic technique, the right C8 DRG and associated dorsal root were fully exposed. Using the surgical microscope, a small slit was made in the dura immediately caudal to the C8 dorsal root. The tines of a sturdy \#3 jeweler's forceps were inserted above and below the root, and the root was crushed, halfway between the dorsal root entry zone and DRG ( $\sim 5 \mathrm{~mm}$ from the DREZ and DRG) for $10 \mathrm{~s}$. The crush was repeated twice more. A complete injury was confirmed by directly visualizing a clearing of the root at the crush site. Immediately after the crush, $1 \mu \mathrm{l}$ of ChABC $(20 \mathrm{U} / \mathrm{ml})$ was injected at the rostral and caudal extent of the DREZ. The injection was performed via a pulled glass pipette (outer diameter, $\sim 60-70 \mu \mathrm{m}$ ) attached to a Nanoject II (Drummond Scientific, Broomall, PA). The injection was performed over $20 \mathrm{~min}$, and the pipette was left in place an additional $3 \mathrm{~min}$ before removal. A small piece of gel film was placed over the dorsal root and DREZ after the injection. The muscle was closed in layers, and the skin was closed with staples. Animals received an intramuscular injection of penicillin-G immediately after surgery and were given analgesics in their water.

Postlesion treatment. Two different postlesion treatment paradigms were examined (supplemental Table 1, available at www.jneurosci.org as supplemental material). In the first (post-treat 1$)$, animals $(n=8)$ underwent C8 dorsal root crushes as described above. Three days after the crush lesion (a time when the regenerating DRG axons have not yet approached the DREZ), animals were injected with zymosan $(31 \mu \mathrm{g} / \mu \mathrm{l})$ into the C8 DRG (see above). One week later, when the zymosan effect is most dramatic and axons are arriving at the DREZ, animals received ChABC $(20 \mathrm{U} / \mathrm{ml})$ injections into the DREZ according to the protocol described above. Animals were examined for regeneration (as described below) 2 weeks after ChABC injection. In the second postlesion treatment plan (post-treat 2), animals $(n=6)$ underwent C8 dorsal root crush lesions, immediately followed by C8 DRG zymosan $(31 \mu \mathrm{g} / \mu \mathrm{l})$ injection, followed $3 \mathrm{~d}$ later by simultaneous C8 DRG zymosan $(31 \mu \mathrm{g} /$ $\mu \mathrm{l})$ injection again and ChABC injection $(20 \mathrm{U} / \mathrm{ml})$ in the DREZ. Animals were examined for regeneration 2 weeks after the initial lesion as described below.

Examination of regeneration through the DREZ. At predetermined times (supplemental Table 1, available at www.jneurosci.org as supplemental material) after the initial injury, animals were anesthetized as previously detailed. Aseptically, the midline incision was reopened to expose the C8 DRG. One microliter of dextran-Texas Red (10\% in water; $3000 \mathrm{kDa}$ molecular weight; Molecular Probes) was slowly injected into the C8 DRG using a $5 \mu$ l Hamilton syringe over $10 \mathrm{~min}$. The muscle was closed in layers and the skin with staples. The following day, the animals were killed with an overdose of isofluorane and transcardially perfused with ice-cold 4\% PFA. Under magnification, the spinal cord and two roots above and two below $\mathrm{C} 8$ were removed. The tissue was postfixed overnight at $4^{\circ} \mathrm{C}$ in $4 \%$ PFA and then cryoprotected in 30\% sucrose in PBS for an additional $24 \mathrm{~h}$. Axial $30 \mu \mathrm{m}$ sections were cut on a cryostat. The sections were then examined under the fluorescence microscope for regeneration through the dorsal root and into the spinal cord. A subset of sections was stained for the presence of proteoglycan (CS-56), proteoglycan degradation (anti-2-B-6), and astrocytosis (anti-GFAP; 1:500; Sigma). Appropriate secondary antibodies conjugated to Alexa 594 or 488 were used (1:500; Molecular Probes).

\section{Quantification of regeneration}

Three regions of the spinal cords were chosen; these were at the rostral extent of the C8 DREZ (referred to as the midsection), $1020 \mu \mathrm{m}$ rostral to the midsection, and $330 \mu \mathrm{m}$ caudal to the midsection. These distances were determined by assessing the animal with the least amount of regeneration in the zymosan plus ChABC combination treatment group. The rostral and caudal extent of regeneration with respect to the midsection were used as an invariant standard that allowed for unbiased quantitative comparisons to be made between the treatment groups. Images at $10 \times$ collected with a digital camera set to a standard exposure time were taken at the three described spinal cord regions in each treatment group by an individual (D.J.S.) who was blinded to the particular treatment each animal had received. Montage images of each section were created, and image thresholds were used to eliminate background noise (Adobe Photoshop). The pixel area in each region above a set threshold was quantified (MetaMorph; Universal Imaging Corporation). Average threshold pixel densities were calculated per region, and, after unblinding, the results from each treatment group were compared using the Student's $t$ test.

\section{$H$-reflex recording}

To test for functional connectivity of regenerated axons, H-reflex recordings were performed. The H-reflex is the electrical representation of the tendon reflex circuit. It is transmitted by large type Ib sensory neurons, assesses both the sensory and motor component of the spinal segment, and is generally considered to be a monosynaptic phenomenon. The $\mathrm{H}$-reflex is obtained by submaximally stimulating a mixed motor sensory nerve, which then produces a muscle contraction (H-wave) with a much greater latency compared with a direct motor response (Thompson et al., 1992).

Control animals underwent $\mathrm{H}$-reflex testing 2 weeks after C8 dorsal root crush lesions, and combination-treated animals were tested $2 \mathrm{~d}(n=$ $3)$ or 2 weeks $(n=5)$ after lesion and DREZ ChABC injection (supplemental Table 1, available at www.jneurosci.org as supplemental material). All animals were anesthetized, and the midline incision was reopened to fully expose the C8 root and DRG. The T1 lamina was removed to expose the T1 nerve root as well. The dura was opened sharply to fully expose the C8 and thoracic level 1 (T1) dorsal roots from the DREZ to their respective DRGs. Two needle electrodes were placed into the right triceps muscle, and a needle was placed into the cervical/paraspinal musculature to serve as a ground. The impendence was checked to verify functioning electrodes. A recording of $<5 \Omega$ was considered to be acceptable. A bipolar electrode was next used to stimulate the T1 dorsal root. The intensity of stimulation was increased until muscle contractions were visualized. The intensity was then reduced until contractions were no longer seen but a muscle action potential was recorded on the screen. Two trials of T1 stimulation were recorded for each animal to serve as a control. Next the C8 dorsal root was stimulated at the submotor threshold as determined above immediately distal to the injury site. Two trials of C8 stimulation and recording were performed for each animal. After the recording, the C8 DRG in all animals was microinjected with dextran-Texas Red as described above. The following day, those animals with an absent H-reflex (control, $n=5$; combination treated, $n=3$, each at $2 \mathrm{~d}$ and 2 weeks) were transcardially perfused as detailed above, and the spinal cord was removed one root above and below $\mathrm{C} 8$. The cords were postfixed overnight at $4^{\circ} \mathrm{C}$ in $4 \%$ PFA and then cryoprotected in $30 \%$ sucrose in PBS for an additional $24 \mathrm{~h}$. Axial $30 \mu \mathrm{m}$ sections were cut on a cryostat. The sections were then examined under fluorescent microscopy for regeneration through the dorsal root and into the spinal cord.

\section{C8 relesion}

To verify that the recorded physiology was attributable to regeneration through the $\mathrm{C} 8$ dorsal root and not attributable to sprouting of adjacent roots or shunting of current, $1 \mathrm{~d}$ after positive $\mathrm{H}$-reflex recording in the remaining two combination-treated animals (at 2 weeks), the C8 dorsal root was again exposed and stimulated with the identical protocol outlined above. After the H-reflex was again elicited, the C8 dorsal root was 


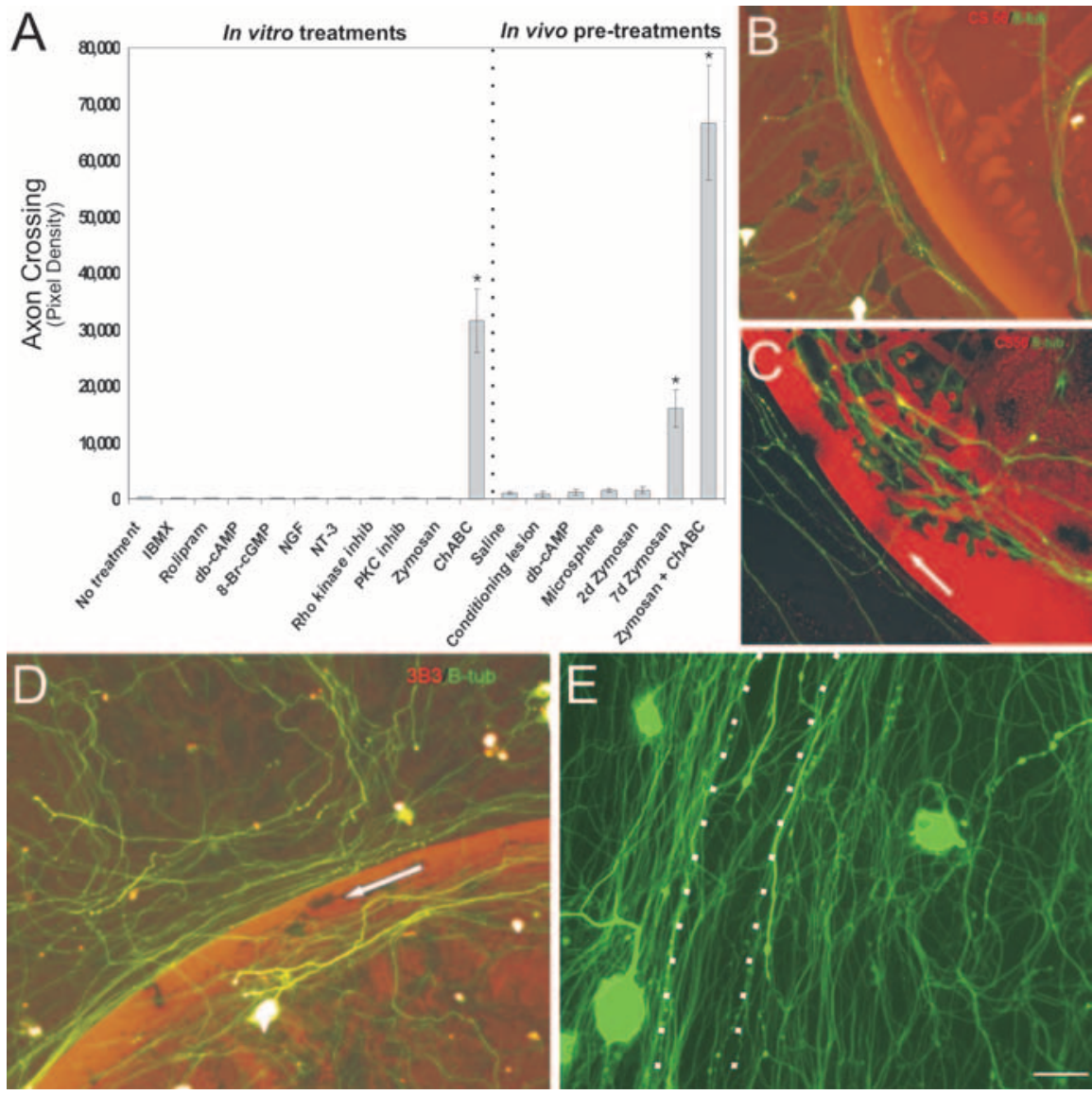

Figure 1. Combination of zymosan and ChABC enhances axon crossing of the inhibitory rim. $A$, Quantification of axon crossing of the inhibitory rim was quantified by mean pixel density. The most robust regeneration was seen with the combinatorial treatment. Statistical differences between each group and control were as follows: $7 \mathrm{~d}$ zymosan, $p<0.0001$; $\mathrm{ChABC}, p<0.001$; zymosan plus $\mathrm{ChABC}, p<0.001 . \boldsymbol{B}$, Representative image of axons (green) unable to traverse the inhibitory rim (red representing (SPGS). C, Representative image of slight but significant crossing of the inhibitory rim (red) by axons (green, arrow) pretreated with zymosan. Similar results were observed with ChABC treatment. $D$, Zymosan pretreatment coupled with ChABC CSPG degradation (red representing digested (SPG) produced robust axon (green $\beta$-tubulin III) crossing of the inhibitory rim (arrow). $\boldsymbol{E}$, Seven day zymosan pretreatment with ChABC application can result in obliteration of the spot rim (arrow) by $\beta$-tubulin IIIpositive adult DRG processes (green). Scale bar: $\boldsymbol{B}-\boldsymbol{E}, 50 \mu \mathrm{m}$. ing solution ( $5 \%$ normal donkey serum, $0.1 \%$ bovine serum albumin, and $0.1 \%$ Triton $\mathrm{X}-100$ in $1 \times$ PBS) and further prepared and visualized as described above.

\section{Results}

Growth-promoting agents do not stimulate neurite crossing of an inhibitory gradient of CSPGs in vitro We first attempted to promote neurite crossing of the inhibitory rim of the spot assay by incubating DRGs in culture with a variety of compounds that have been shown previously to improve neurite outgrowth on inhibitory substrates. These included the following: general and specific phosphodiesterase inhibitors, IBMX and Rolipram (Nikulina et al., 2004); cyclic nucleotide analogs that activate protein kinase $A$ and protein kinase $G$, db-cAMP and 8-Br-cGMP (Song et al., 1998; Cai et al., 1999); two neurotrophins, NGF and NT-3 (Tuszynski, 1999; Gao et al., 2003, Peng et al., 2003); a Rho kinase inhibitor, Y-27632 (Fournier et al., 2003); a protein kinase C inhibitor, Gö6976 (Sivasankaran et al., 2004); and an inflammatory agent, zymosan, made from a yeast cell wall extract that stimulates a conditioning-lesion effect (Leon et al., 2000; Yin et al., 2003).

Concentrations of the aforementioned reagents shown by others to be effective in their chosen bioassays were selected. After $5 \mathrm{~d}$ of culture, coverslips were fixed, and the number of axons that crossed over the intensely inhibitory outer rim of the spot were quantified. Neurons were visualized with anti- $\beta$-tubulin III and the rim of the spot with CS-56. None of the aforementioned treatments administered in vitro allowed any axons to cross the inhibitory $\operatorname{rim}($ Fig. 1A). sectioned completely with microscissors. Stimulation of the distal C8 stump and recording in the triceps muscle was again performed. Loss of the H-reflex was indicative of regeneration through the C8 dorsal root. These animals were then quickly killed for anatomical analysis as described above. All neurophysiologic recordings were printed on standard paper and presented to a blinded neurophysiologist (D.N.) in a random order. The neurophysiologist then graded each tracing as a positive $(\mathrm{H}-$ reflex present) or a negative response. The physiologic tracings were subsequently correlated with their respective anatomy.

\section{Growth-associated protein analysis}

Five adult female Sprague Dawley rats (275-300 g) underwent hemilaminectomy to expose the right-side C6-C8 DRG. The ganglia were subsequently injected with zymosan in sterile saline as described above (supplemental Table 1, available at www.jneurosci.org as supplemental material). Five sterile saline-injected animals served as controls. After $7 \mathrm{~d}$, the rats were killed with isofluorane and perfused transcardially with cold $4 \%$ PFA. The spinal cord with attached bilateral C6, C7, and C8 DRG was excised and postfixed at $4{ }^{\circ} \mathrm{C}$ in $4 \%$ PFA for $24-48 \mathrm{~h}$. The cords were cryoprotected (30\% sucrose in PBS) before cryostat sectioning and immunofluorescent staining. Tissue sections were incubated overnight at $4^{\circ} \mathrm{C}$ in anti-growth-associated protein (GAP-43) (1:3000; kind gift from Dr. L. Benowitz, Harvard University, Boston, MA) diluted in PBS block-

\section{Removal of inhibitory glycosaminoglycans from the CSPG gradient enhances neurite crossing}

Decreasing proteoglycan-mediated inhibition of the glial scar, in vivo, has been shown to allow a limited number of would-be dystrophic axons to regenerate further into or even around lesions in the brain (Moon et al., 2001) or spinal cord (Bradbury et al., 2002; Grimpe and Silver, 2004). Interestingly, in our in vitro gradient model in which axonal dystrophy is the typical end result of frustrated axonal regrowth, ChABC treatment alone $(n=$ $11)$ also permitted only a small, albeit significant $(p<0.001)$, number of fibers to cross (Fig. $1 A$ ).

\section{In vivo exposure to known stimulators of the intrinsic regeneration potential in DRG axons can enhance neurite crossing in vitro}

Because in vitro treatment with known stimulators of regeneration or ChABC did not result in especially remarkable crossing of the inhibitory rim, we hypothesized that a previous, relatively long-term manipulation of the DRG in vivo, with the goal of driving a conditioning lesion-like effect to its potential maxi- 
mum, would be necessary to adequately prime the intrinsic regrowth machinery of the DRG neuron. To do this, we selected several of the most promising strategies that have been shown to be effective in other models of regeneration in vivo and applied them to the DRG in advance of harvesting the cells.

The left L4, L5, and L6 DRGs of adult female Sprague Dawley rats were microinjected with db-cAMP $(n=8)$, zymosan $(n=8)$, latex microspheres (an inert particulate; $n=8$ ), or saline (vehicle; $n=8$ ). Another group of animals instead received a sciatic nerve crush-conditioning lesion $(n=8)$. At 2 or $7 \mathrm{~d}$ after injection or nerve crush, DRGs were harvested for cell culture experiments on our spot gradient assay. The untouched contralateral DRGs served as untreated controls. Five days after culture, the coverslips were fixed and assessed for the density of axons that crossed the rim of the spot. Minimal crossing of the rim was seen in those cultures in which DRGs had received saline $(n=11)$, latex microspheres $(n=11)$, or no treatment $(n=11)$ at both 2 and $7 \mathrm{~d}$ before harvest (Fig. $1 A, B$ ). Although not statistically significant, a slightly increased number of crossing fibers was observed after a single intraganglionic injection of db-cAMP ( 2 and $7 \mathrm{~d} ; n=11)$, a conditioning sciatic nerve lesion ( 2 and $7 \mathrm{~d} ; n=11$ ), and zymosan pretreatment at the $2 \mathrm{~d}$ time point $(n=11)$ (Fig. $1 A, B)$.

In those DRGs that were exposed to zymosan $7 \mathrm{~d}$ before harvest $(n=12)$, a significantly greater number of fibers traversed the inhibitory $\operatorname{rim}(p<0.0001)$ (Fig. $1 A, C)$. Statistical analysis revealed that the amount of fiber crossing in the zymosan-alone (7 d) and in ChABC-alone treatment groups was equivalent $(p=$ 1.0) (Fig. 1A). However, when $7 \mathrm{~d}$ zymosan in vivo pretreatment was combined with digestion of the spot using ChABC $(n=11)$, a vastly improved amount of regeneration occurred $(p<0.001)$ (Fig. $1 A, D, E$ ), suggesting that the two treatments may have acted synergistically.

\section{Zymosan and ChABC treatment results in increased number of satellite glia in culture}

Subjectively, it was noted that there were increased numbers of satellite glia and/or Schwann cells present in those DRG cell cultures treated with zymosan as well as those treated with zymosan combined with ChABC. Therefore, the number of satellite glia/ Schwann cells (determined via S-100 immunostaining) was quantified only in the rim region of the spot in zymosan-onlytreated cultures $(n=6)$, zymosan/ChABC-treated cultures $(n=$ $6)$, and in untreated controls $(n=6)$. Analysis of threshold pixel density revealed that the difference in the numbers of supporting glia was statistically significant between controls and those treated with zymosan plus ChABC $(p<0.001)$ (Fig. 2A). Whereas satellite/Schwann cell processes were occasionally able to grow over the rim of the spot in cultures receiving zymosan plus $\mathrm{ChABC}$, the majority of regenerating axons crossed the rim at a distance from their nearest glial cell neighbor (Fig. $2 B$ ).

\section{Microinjection of zymosan results in increased expression of GAP-43 in the sensory root}

To determine whether zymosan stimulates the regeneration potential of DRG neurons in vivo without the need for a peripheral crush lesion, DRGs and their attached uninjured roots were examined for expression of GAP-43 after zymosan injection. GAP-43 is critical for proper growth cone motility and is known to be expressed in regenerating axons (Skene et al., 1986). Cryostat sections from animals $7 \mathrm{~d}$ after microinjection of zymosan or saline as well as untreated controls were stained for GAP-43 protein. Untreated control and saline-injected DRGs and their adjoining roots had limited, if any, detectable GAP-43 expression
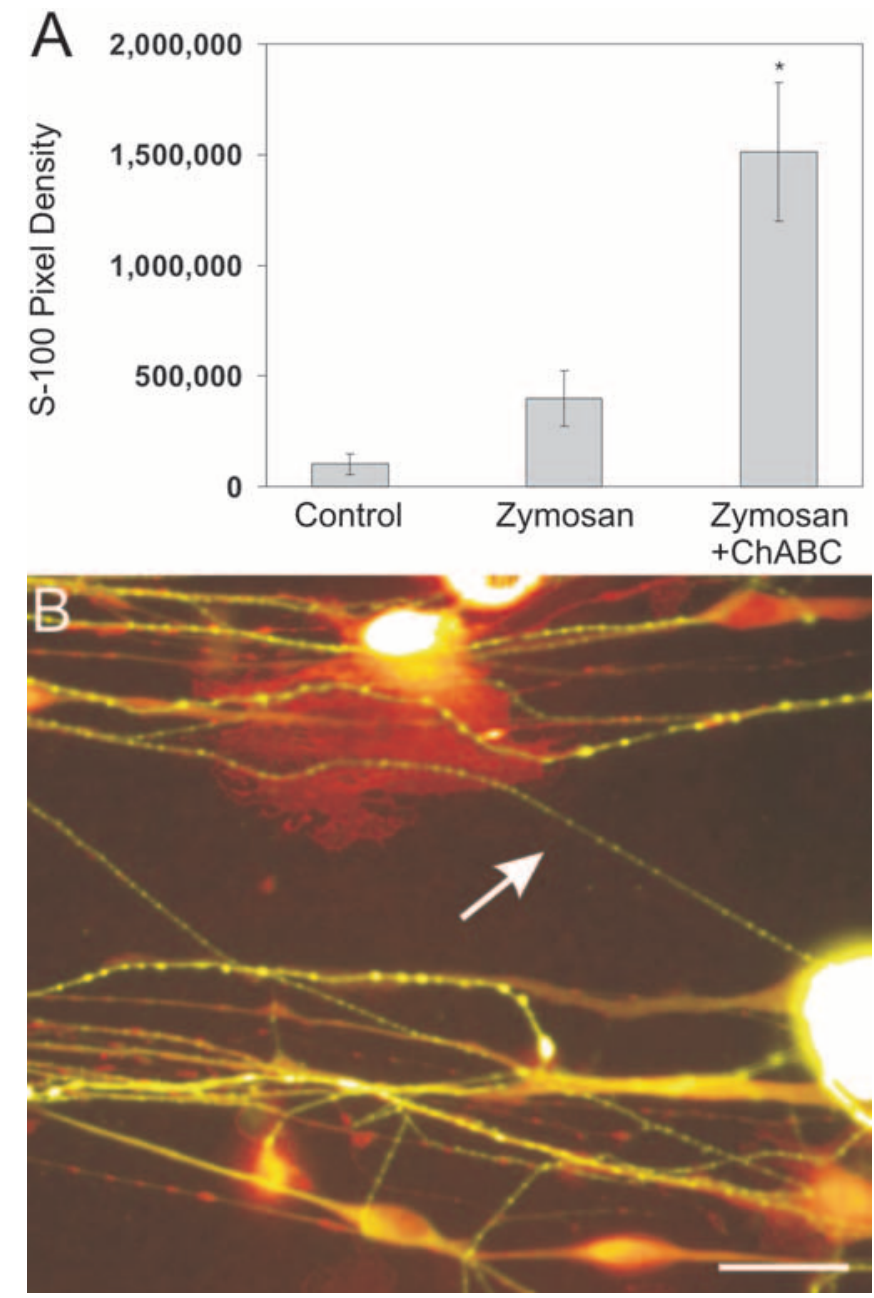

Figure 2. Combination treatment increases the number of satellite glia. $A$, Quantification of $S-100$ staining using pixel density. Significantly greater numbers of satellite glia were present after the combinatorial treatment $(p<0.001)$. B Image demonstrating satellite glia (red) in the vicinity of the rim and the fact that, although there were more glia in general, DRG sensory axons (green) were capable of crossing the inhibitory rim in the absence of close contact with the satellite cells. Scale bar, $50 \mu \mathrm{m}$.

(Fig. 3C). After zymosan microinjection, a marked enhancement of GAP-43 staining was especially noticeable in bundles of axons within the dorsal roots (Fig. $3 A, B$ ). GAP-43 staining in the vicinity of the zymosan injection site within the DRG cell bodies was primarily obscured by background labeling because of the rampant inflammatory response (see below).

\section{Microinjection of zymosan results in infiltration of ED-1-positive macrophages into the DRG}

Thirty micrometer cryostat sections of DRGs were examined $7 \mathrm{~d}$ after microinjection with either saline or zymosan. There were insignificant numbers of ED-1-positive macrophages in control samples. However, by 1 week after zymosan microinjection, a large influx of ED-1-positive macrophages had occurred. Moreover, the location of the macrophages corresponded precisely to the location of the zymosan injection (Fig. $3 E-G$ ). Furthermore, analysis of $7 \mathrm{~d}$ zymosan pretreated DRG neurons grown on the spot assay also revealed increased numbers of ED-1-positive macrophages compared with controls, many of which contained ingested zymosan particles (data not shown). Interestingly, no close association between crossing axons and zymosan- 

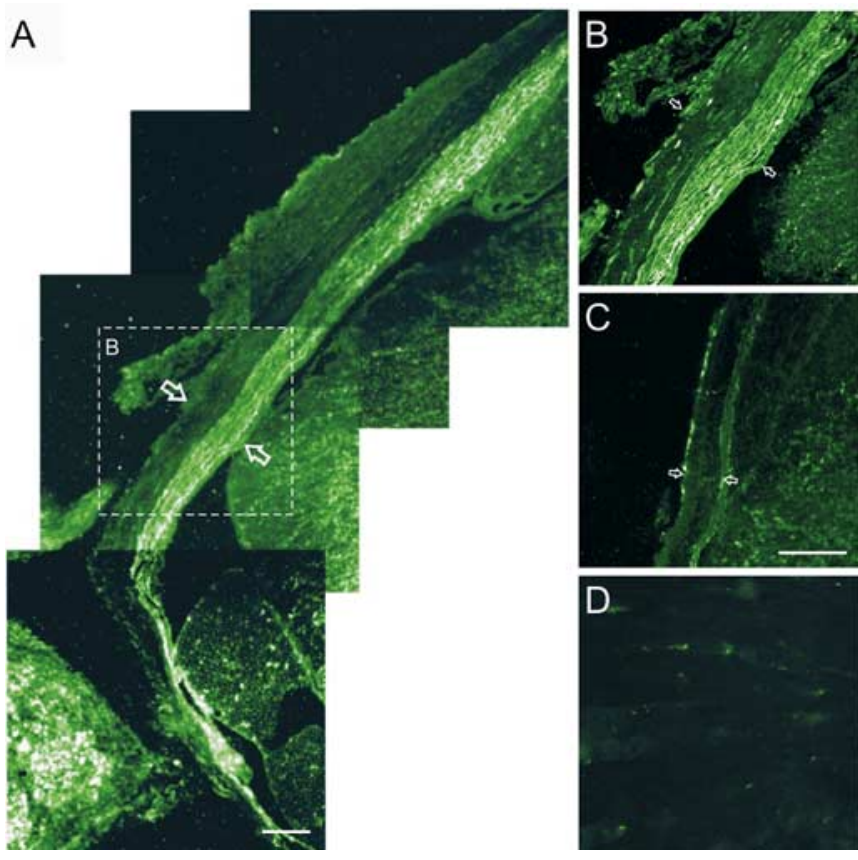

Figure 3. Local effects of zymosan application on the DRG. $\boldsymbol{A}$, Confocal photomontage of a zymosan-injected DRG and its contiguous dorsal root demonstrating an increase in the growth-associated protein GAP-43 (green). $\boldsymbol{B}$, Inset of $\boldsymbol{A}$ at a higher magnification to better accentuate the increases in GAP-43 expression with zymosan injection. $C$, A saline-treated control DRG demonstrates a paucity of GAP-43 expression in the root. $D$, Control DRG immunostained for ED-1 (green), indicating an absence of invading activated immune cells. $\boldsymbol{E}$, At $7 \mathrm{~d}$ after zymosan injection, a marked influx of ED-1-positive macrophages can be identified in the DRG (green). $\boldsymbol{F}$, Photomicrograph of the same DRG showing Texas Red-conjugated zymosan particles. G, Overlay of $\boldsymbol{E}$ and $\boldsymbol{F}$ demonstrates that the zymosan particles colocalize with the invading ED-1-positive macrophages. Scale bars: $\boldsymbol{A}-\boldsymbol{C}, 50$ $\mu \mathrm{m} ; \mathbf{D}-\mathbf{G}, 100 \mu \mathrm{m}$.
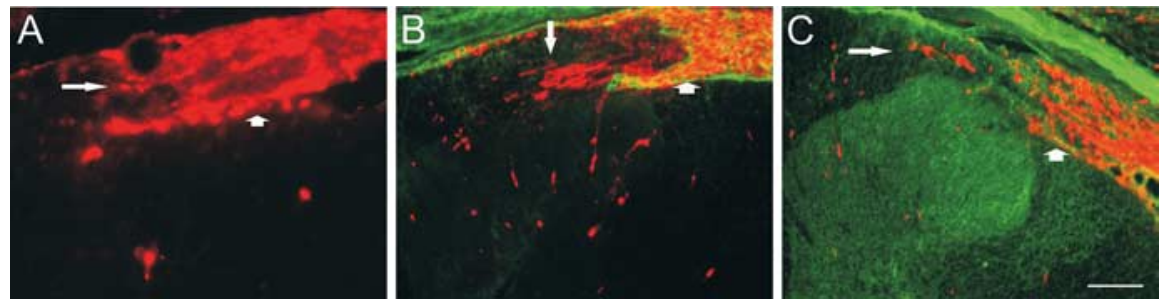

Figure 4. Multiple strategies to attempt to promote regeneration across the DREZ. $A, A$ C 8 dorsal root crush that received no treatment demonstrates a lack of regeneration through the DREZ (thin arrow) into the spinal cord despite the ability to extend axons through the crushed root (fat arrow). Axons are labeled with dextran-Texas Red. $\boldsymbol{B}$, Animals that received zymosan alone $7 \mathrm{~d}$ before injury demonstrated slight regeneration through the DREZ (thin arrow) into the dorsal gray. The DREZ is highlighted by the presence of CSPG staining (green). C, Animals that received ChABC alone demonstrated very slight regeneration of fibers (thin arrow) through the DREZ (thick arrow). Areas of CSPG digestion from the ChABC injection can be readily identified by anti-2-B-6 staining (green). Scale bar, $50 \mu \mathrm{m}$.

containing macrophages was noted in culture (data not shown), indicating that any potential stimulatory effects macrophages may have on neurons likely occurs in vivo, before the cells are harvested.

\section{Regeneration across the DREZ in vivo}

Because the spot assay contains large numbers of satellite glia and/or Schwann cells in which the sensory fibers initiate and because the fibers encounter increasing amounts of proteoglycan as they extend within the rim, in many respects the organization of cells and matrices in the gradient assay resembles the DREZ after root lesion (Pindzola et al., 1990). This assay is therefore useful to screen potential treatment paradigms. After identification of a successful in vitro treatment, we chose to test the efficacy
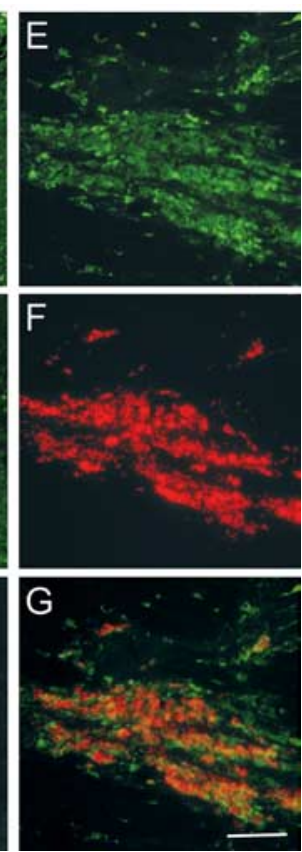

of this combination strategy in promoting regeneration through the DREZ in vivo.

Two weeks after $\mathrm{C} 8$ root crush, animals receiving zymosan plus ChABC, zymosan alone, ChABC alone, as well as untreated controls were killed and analyzed for axon regeneration after transganglionic labeling with dextran-Texas Red. No axons were found to have regenerated past the DREZ in untreated animals $(n=20)$. Many axons simply formed dystrophic endings at the site of the crush, whereas a large majority extended all the way to the DREZ, in which they too formed dystrophic endings (Fig. 4A).

In five of eight animals receiving a $7 \mathrm{~d}$ zymosan pretreatment, a relatively small but significant $(p<0.0001)$ number of fibers extended across the DREZ and into the spinal cord (Fig. 4B). Axons were observed to travel small distances past the DREZ and terminate mainly in the dorsal gray matter (between laminas I and IV). Very few axons penetrated substantially into the dorsal column white matter. In 3 of 12 animals receiving $\mathrm{ChABC}$ injection into the DREZ, axons reextended into the spinal cord. In one animal, the axons were quantifiable, and in two animals, the numbers fell below our set threshold for quantification. The majority of these axons ended in the dorsal gray matter with very few observed in the dorsal columns (Fig. 4C). Anti-2-B-6 labeling for digested CSPGs demonstrated a degradation of proteoglycan in the DREZ, dorsal columns, dorsal horn, and lateral funiculus (Fig. 4C) (see below). Despite the degradation of inhibitory CSPG at the DREZ, a relatively insignificant number of axons regenerated into the spinal cord. As shown in our culture experiments, it appears that some stimulation of the neuron is also required for highly significant regeneration to occur. To this end, we combined zymosan microinjection into the DRG along with $\mathrm{ChABC}$ microinjection into the DREZ.

In contrast to those animals that received only zymosan or ChABC microinjection alone, extremely robust regeneration was demonstrated in 8 of 12 animals receiving zymosan pretreatment plus ChABC. Sensory axons regenerated through the DREZ, well into the spinal cord dorsal horn, and sometimes, but not always (see below), splayed into lush arborizations of terminals (Fig. 5A). Labeled processes also extended rostrally and caudally within the white matter of the dorsal columns (Fig. 5C). The quantity of regenerating axons was significantly greater in the combination group compared with all other groups (Fig. 6). Anti-2-B-6 labeling confirmed proteoglycan degradation at the site of $\mathrm{ChABC}$ injection at the DREZ, dorsal gray matter, dorsal columns, and lateral funiculus (Fig. 5B).

Additional evidence of regeneration is the presence of unusual trajectories or other oddities of sensory axon reinnervation in the 
spinal cord. Fibers were observed that had passed through the gray matter and appeared to enter into the ventral white matter (data not shown). Regenerated axons were found that circled around sites of ChABC injection (confirmed with anti-2B-6 labeling) (Fig. 5B). Axons were also seen that had twisted on themselves and extended as thick fascicles from the medial aspect of the root and DREZ deep into the dorsal gray (see Fig. 8). Fascicles like these often ended abruptly without spreading into terminal arbors. Last, regenerating fibers that did enter the dorsal column white matter extended relatively long distances both rostrally and caudally, in stark contrast to the other treatment groups. However, they were labeled over significantly less distance compared with uninjured controls (Fig. 6, inset).

\section{Physiologic evidence of regeneration}

Because regeneration in our single DRG model cannot be evaluated behaviorally, we chose to use a well characterized physiological assessment of the H-reflex (Thompson et al., 1992). Eight additional animals that had received the combination treatment and five untreated animals underwent physiologic testing and anatomical tracing of $\mathrm{C} 8$ root regeneration $2 \mathrm{~d}$ or 2 weeks after $\mathrm{C} 8$ crush injury. None of the untreated controls $(n=5)$ demonstrated physiologic or anatomic evidence of regeneration. Three animals in the combination group underwent physiologic testing $2 \mathrm{~d}$ after root crush. No animals at $2 \mathrm{~d}$ demonstrated an H-reflex at this early time point, nor was there anatomic evidence of axon extension into the spinal cord. Five animals in the combination treatment group underwent physiologic testing 2 weeks after C8 crush injury. Two of these animals demonstrated an H-reflex, with anatomic evidence of axon regeneration into the dorsal horn of the spinal cord (Fig. $7 \mathrm{~A}, \mathrm{C}$ ). Relesioning the $\mathrm{C} 8$ root caused the reflex to disappear (Fig. $7 B$ ). Surprisingly, in one animal lacking evidence of an H-reflex, there was obvious anatomic evidence of regeneration. In this animal, the regenerating fibers were tightly bundled and terminated in the dorsal horn with very simple, nonarborized shapes (Fig. 8), indicating an absence of mature, functional synapses.

The $\mathrm{T} 1$ sensory nerve was stimulated in all animals to serve as a control. The average latency of the normal $\mathrm{H}$-reflex circuit was $5.37 \mathrm{~ms}$, whereas the average amplitude was $17.19 \mathrm{mV}$. The average latency of the restored H-reflex in the two animals with fiber regeneration was $7.92 \mathrm{~ms}$, whereas the average amplitude was $1.83 \mathrm{mV}$. The increased latency and decreased amplitude in those nerves that demonstrated functional recovery most likely indicate that, at 2 weeks of regeneration, the dorsal horn had been innervated with less than optimal numbers of axons and/or inadequate numbers of effective synapses had developed. It is possible that sufficient numbers of the rapidly conducting cohort of fibers were lacking as well. In addition to relatively decreased fiber numbers or synapses, there could be a conduction block across the site of injury, reformed synaptic connections on inappropriate interneurons, or a lack of myelin around the regenerating fibers.

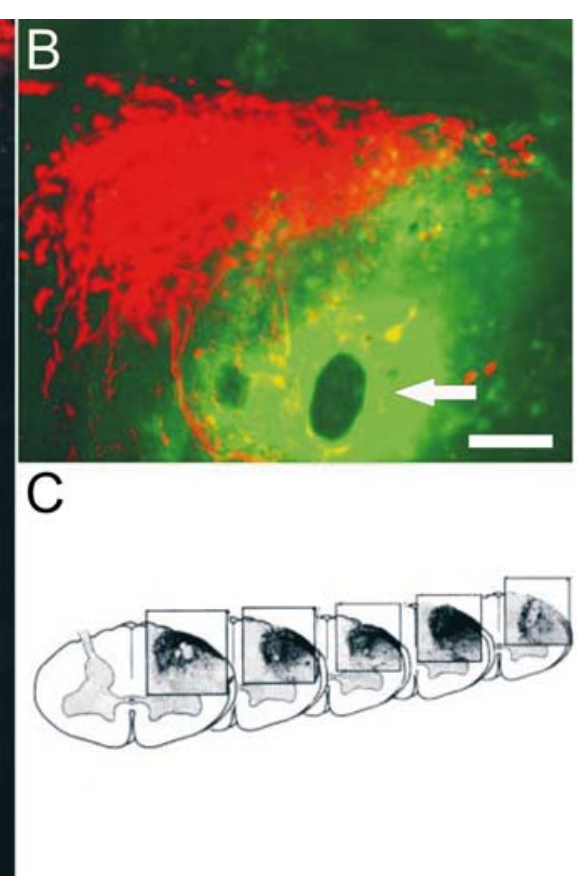

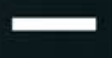

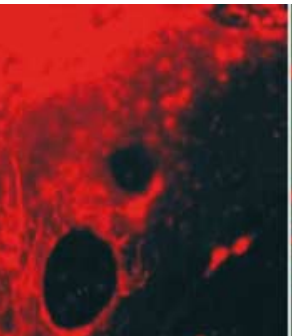

Figure 5. The combination of zymosan pretreatment and ChABC promotes significant regeneration across the DREZ.A, At $14 \mathrm{~d}$ to the region of greatest CSPG digestion (compare $\boldsymbol{A}, \boldsymbol{B}$ ). $\boldsymbol{C}$, Three-dimensional reconstruction of regenerating axons demonstrating the extent of rostral/caudal regeneration. Scale bars, $30 \mu \mathrm{m}$.

\section{Postlesion combination treatment does not promote significant regeneration}

Having had success with the $7 \mathrm{~d}$ zymosan pretreatment plus ChABC combinatorial strategy, we sought to determine whether treating the DRG after injury would also promote anatomical and functional regeneration of the sensory root. Two different paradigms were examined to determine whether the timing of zymosan and ChABC application influenced whether or not regeneration would occur. In both paradigms, postlesion combination treatments were insufficient to promote regeneration (Figs. 6, 9).

\section{Discussion}

We have identified an optimal strategy that stimulates adult sensory axon regeneration in vitro across a gradient of increasing proteoglycans and decreasing laminin. The gradient model (Tom et al., 2004a), unlike sharp-edged assays that result in turning behavior (Snow et al., 1990; Kantor et al., 2004), causes adult sensory growth cones to form dystrophic end bulbs, the hallmark of regeneration failure (Ramón y Cajal, 1928). We used this assay, one that may represent a more realistic model of the glial scar, to test a variety of reagents and neuron conditioning strategies that stimulate regeneration in other inhibitory environments. Only two of the many agents tested could foster some regeneration across the most inhospitable region of the gradient. These were ChABC removal of glycosaminoglycans and weeklong zymosan pretreatment of the DRG. When used in combination, the results were remarkable.

The DREZ is a potent barrier to the regeneration of sensory axons (Kliot et al., 1990; Golding et al., 1997, 1999). At this point, not only is there a need to overcome the inhibitory extrinsic and intrinsic limitations to regeneration, the fibers must also be induced to leave the highly growth-promoting Schwann cell membranes (Harvey and Plant, 1995; Grimpe et al., 2005), a surface to 


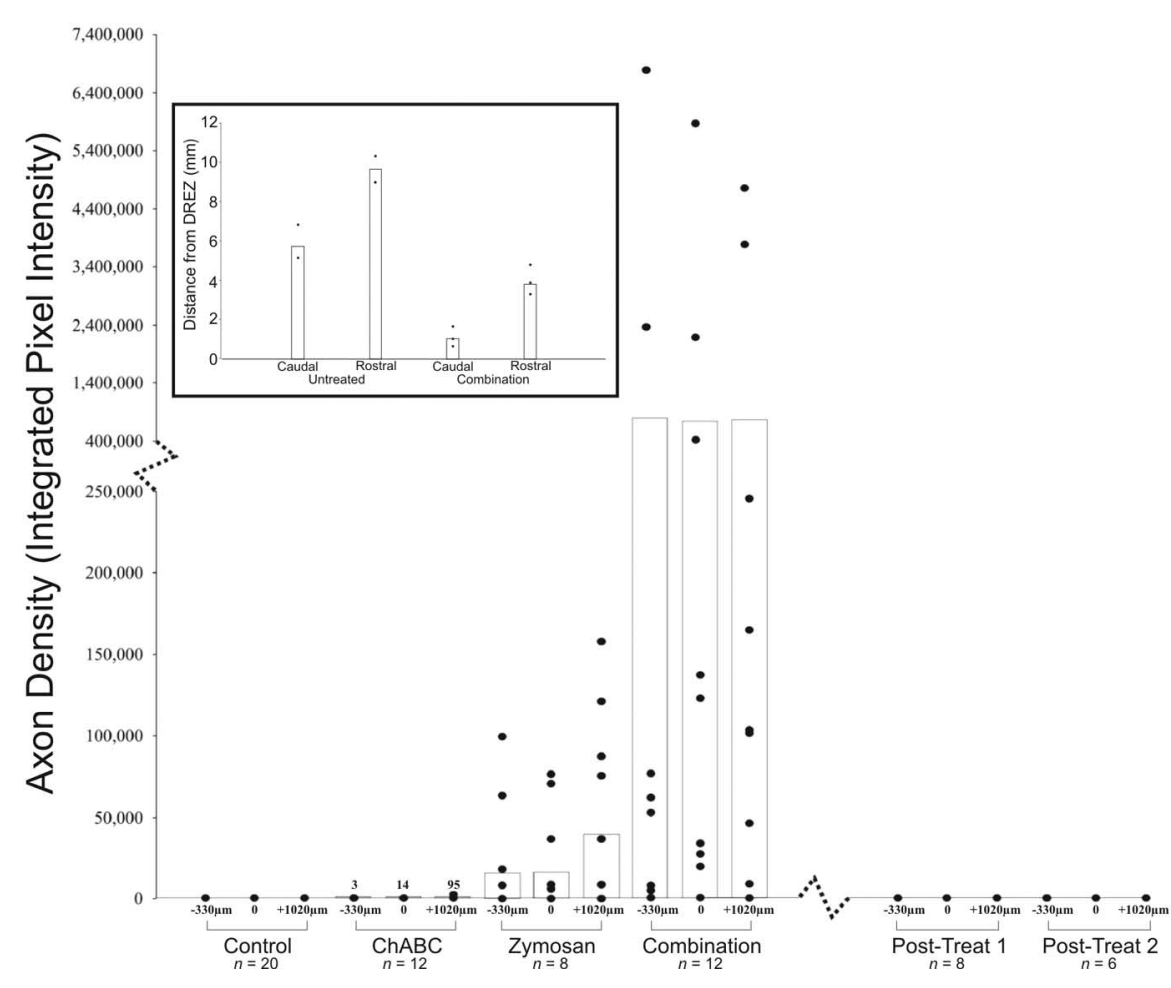

Figure 6. Quantification of axon regeneration across the DREZ. Spinal cords were analyzed at the DREZ and at set positions rostral to and caudal to the DREZ. No regeneration was identified in the control and postlesion groups. Very minimal regeneration was identified in the ChABC-alone group. Significantly more regeneration was identified in the zymosan-alone group, but the greatest regeneration occurred in the combination treatment group. Each point represents the extent of regeneration in an animal, and the bar graphs represent the mean of regeneration. Inset, Regeneration through the white matter of the dorsal columns was quantified by measuring the extent of dextran-Texas Red labeling. Distances of axonal regeneration in animals receiving the combination therapy were compared with untreated, uninjured rats injected with dextran-Texas Red. In uninjured animals, the dye traveled an average of $6 \mathrm{~mm}$ caudal to and $10 \mathrm{~mm}$ rostral to the DREZ. In animals treated with the combination of zymosan and ChABC, the average regeneration was $1 \mathrm{~mm}$ caudal to and $4 \mathrm{~mm}$ rostral to the DREZ.
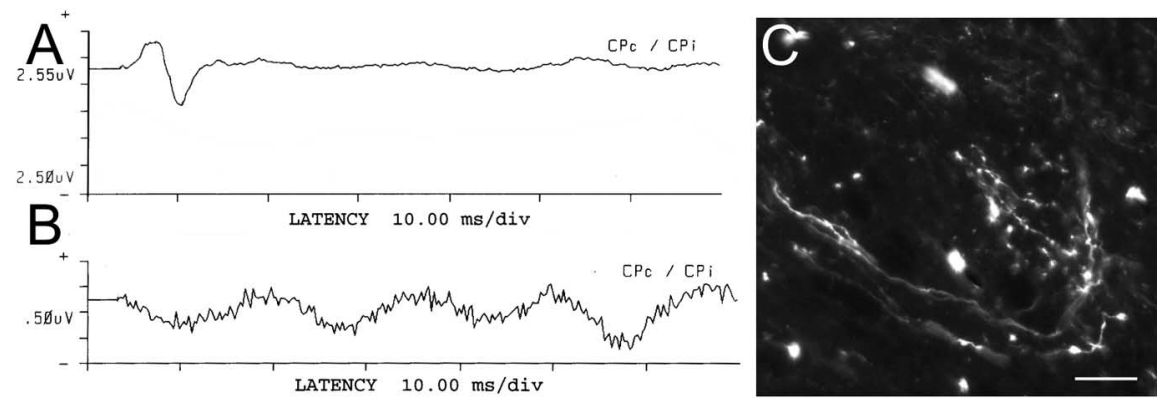

Figure 7. Combination treatment-induced regeneration resulted in restoration of the H-reflex. $A$, Two weeks after injury, the combination treatment group animals had a restored $\mathrm{H}$-reflex. $\boldsymbol{B}$, The next day, the $\mathrm{C} 8$ root was severed to verify that the $\mathrm{H}$-reflex identified in $\boldsymbol{A}$ was transmitted directly via the regenerated root. Severing the root resulted in the disappearance of the $\mathrm{H}$-reflex. C, In animals that had a restored $\mathrm{H}$-reflex, regenerating axons with clear evidence of terminal arborizations were subsequently identified in the dorsal horn. Scale bar, $50 \mu \mathrm{m}$.

which they tend to become "addicted" even when proteoglycan levels at the Schwann cell/astroglial border are reduced (Grimpe et al., 2005). The use of neurotrophic lures placed in the dorsal horn (Romero et al., 2000, 2001; Ramer et al., 2002; McPhail et al., 2005) has shown that increasing NGF or NT-3 levels in the spinal cord endows lesioned sensory fibers with the ability to overcome barriers to regeneration, stimulating substantial, centrally directed regrowth. An important limitation of regeneration-promoting strategies in which high levels of extra- neous neurotrophins have been used (Oudega and Hagg, 1999; Bamber et al., 2001; Blesch and Tuszynski, 2003) is that of entrapment or overgrowth of fibers within the vicinity of neurotrophin expression (Romero et al., 2000, 2001).

We report that the combination of zymosan preconditioning of the DRG plus the modification of inhibitory CSPGs within the dorsal horn with $\mathrm{ChABC}$ allows for the regeneration of sensory axons through the DREZ, ranging well beyond that which has been documented previously. After escaping from Schwann cells, and in the absence of an oasis of neurotrophins, the zymosan-stimulated sensory fibers appear to be free to elongate using growth cues within the deafferented adult spinal cord (Tom et al., 2004b). Also, our physiological assessment of the H-reflexrelated circuitry transmitted via $\mathrm{C} 8$ neurons showed that the synaptic targeting of the regenerated fibers was precise enough to generate functionally appropriate activity, at least in some animals. Curiously, in some instances in which clearly regenerated fibers were present, there was a lack of apparent terminal arborization and no restoration of reflex activity, at least after 2 weeks. Perhaps synaptogenic factors made during development by immature astroglia are lacking in mature reactive glia within deafferented tissue (Lin et al., 2003; Ullian et al., 2004; Christopherson et al., 2005), or perhaps optimal levels of neurotrophic support (Romero et al., 2001) are lacking in the adult spinal cord. Such factors may need to be provided, but in limited concentrations and perhaps directly within the dendrites of the appropriate postsynaptic neurons themselves to avoid an overly dense reinnervation of the target (Grimpe et al., 2004). The lengthy regeneration of the centrally projecting processes of sensory fibers in the adult CNS once beyond the DREZ reiterates the result that microtransplanted DRGs are capable of amazingly robust outgrowth in the environment of the lesioned adult CNS once they are beyond the vicinity of the glial scar (Davies et al., 1999; Grimpe et al., 2005).

It is not only important to discuss when regeneration was promoted but also where and when it was limited. Although others (Moon et al., 2001; Bradbury et al., 2002; Caggiano et al., 2005; Fouad et al., 2005) have documented the therapeutic effects of proteoglycan modification during regeneration, the numbers of fibers reported to project clearly past a cord lesion in vivo have been quite low. It should be stressed that $\mathrm{ChABC}$ alone in the DREZ model only allowed for a small amount of regeneration as well. Such limited regeneration may be attributable to the threedimensional arrangement of the various glial cell types at the DREZ, the addition of constraints to regeneration brought about 
by oligodendrocyte derived inhibitors (Schwab, 2004; Bertrand et al., 2005), as well as an intrinsic lack of growth potential (Wong and Oblinger, 1990) in unconditioned central DRG processes. Thus, ChABC may improve function after CNS injury via its effects on plasticity, in addition to the promotion of frank regeneration (Bradbury et al., 2002).

Although the effect of a distal conditioning lesion in promoting enhanced sensory root regeneration has been known for several decades (McQuarrie and Grafstein, 1973; Richardson and Issa, 1984), there has been a renewed interest in this phenomenon since it was shown that peripheral conditioning of the DRG can also foster enhanced regeneration within the dorsal columns (Neumann and Woolf, 1999; Filbin, 2003). The important obser-
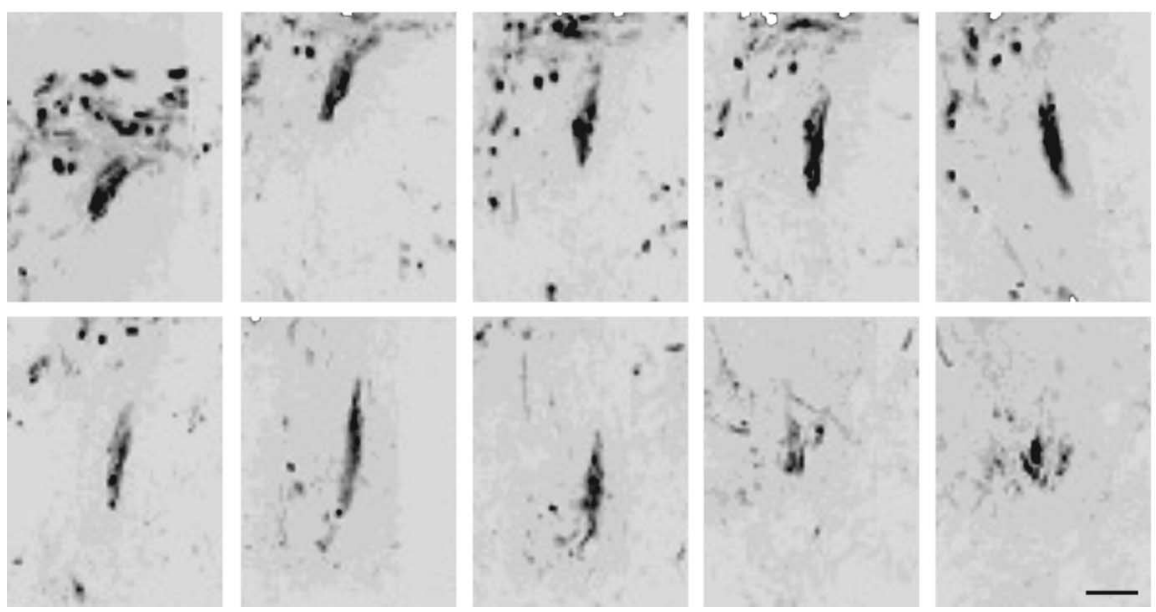

Figure 8. Inverted grayscale confocal images of serial sections through the dorsal horn from an animal with nonfunctional regeneration. Interestingly, in this animal, axonal regeneration was clearly present, although no H-reflex was identified. Notably, regenerating axons formed thick fascicles that ended blindly with few terminal arbors. Scale bar, $50 \mu \mathrm{m}$. the DRG (Lu and Richardson, 1991) and that cAMP injection into the ganglion can mimic the conditioning effect (Filbin, 2003) provided various means by which to enhance central regeneration without having to sacrifice the sciatic nerve.

Our results emphasize the importance of stimulating the intrinsic growth properties of the sensory neuron, in addition to matrix modification by $\mathrm{ChABC}$, to promote maximal regeneration through the DREZ. This supports the work of others who have used different types of conditioning to foster regeneration in the spinal cord (Qiu et al., 2002; Neumann et al., 2002; Chau et al., 2003; Lu et al., 2004; Nikulina et al., 2004; Pearse et al., 2004) and optic system (Leon et al., 2000; Tropea et al., 2003; Berardi et al., 2004; Medini et al., 2004). Also, our results suggest the exciting conclusion that, when a particular form of subchronic inflammation-induced conditioning is present in the DRG in combination with $\mathrm{ChABC}$, the amount of sensory reinnervation of the cord can achieve unprecedented levels.

Although it has been demonstrated that sciatic nerve conditioning or a single injection of cAMP into the DRG can allow for regeneration centrally (Neumann and Woolf, 1999; Neumann et al., 2002; Qiu et al., 2002, 2005), most of the fibers simply project more deeply into the lesion but rarely beyond. It has been suggested that the conditioning effect can be a graded phenomenon (S. Neumann, K. Skinner, and A. I. Busbaum, unpublished observation) and that a more chronic or aggressive form of conditioning may further improve regenerative capacity. Zymosan is a nontoxic but extremely potent inflammatory agent that, when placed within the vitreous chamber adjacent to the retinal ganglion cells, can drive regenerating optic fibers past a crush lesion of the optic nerve (Leon et al., 2000). Our results suggest that zymosan, when placed in the DRG, can upregulate regenerationpromoting proteins, such as GAP-43, in the central axon even in the absence of a lesion (Chong et al., 1994; Vaudano et al., 1995). Unfortunately, zymosan cannot be used in the CNS because it induces cyst formation (Fitch et al., 1999). Although the underlying cellular and molecular mechanisms of zymosan conditioning are unknown, the increased axonal regeneration is not likely attributable to a direct effect on neurons but, rather, an indirect effect possibly also involving the satellite glia mediated via macrophage release of a pro-regenerative protein (Leon et al., 2000). The Benowitz laboratory has recently identified a $14 \mathrm{kDa}$ protein that may be critical. If the protein can substitute for zymosan,

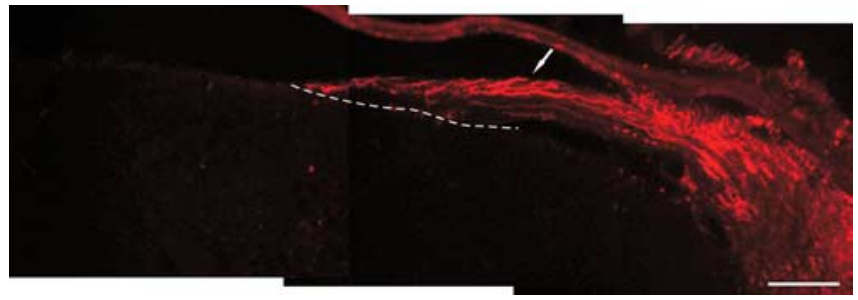

Figure 9. Representative image of postlesion treatment paradigms demonstrates a lack of regeneration when treatment was delayed until after crush injury. Axons (red) can be identified traveling in the crushed root (arrow) directly to the DREZ (dotted line), in which they fail to enter the spinal cord. Scale bar, $100 \mu \mathrm{m}$.

especially in the CNS, then it could prove to be particularly important (Yin et al., 2004).

Despite its success in the pretreatment paradigm, combining zymosan and ChABC treatments was ineffective in a more clinically relevant, postlesion model. What are the essential intrinsic changes in the sensory neuron that might be occurring with lengthy preconditioning that, with the help of proteoglycan degradation, allow growth cones to readily abandon Schwann cells and reenter the CNS? There is evidence that preconditioned regenerating sensory neurons develop an enhanced capacity for protein synthesis locally within the newly forming axon (Zheng et al., 2001; Brittis et al., 2002; Steward and Schuman, 2003). It may take considerable time for local synthetic machinery to reach sufficient levels to rapidly stimulate the production of an adequate repertoire of integrin receptors (Condic, 2001; Ekstrom et al., 2003; Irvins et al., 2004) or cytoskeletal elements (Zheng et al., 2001; Han et al., 2004) needed to allow the regenerating growth cone to move quickly from one substrate to another at the DREZ, avoiding turning or becoming dystrophic (Tom et al., 2004a). If we can elucidate the critical factors for axonal regrowth that are present after protracted conditioning, we may be able to enhance them more efficiently and, with matrix modification via ChABC, promote a more vigorous regeneration response after injury.

\section{References}

Bamber NI, Li HY, Lu XB, Oudega M, Aebischer P, Xu XM (2001) Neurotrophins BDNF and NT-3 promote axonal re-entry into the distal host spinal cord through Schwann cell-seeded mini-channels. Eur J Neurosci 13:257-268. 
Berardi N, Pizzorusso T, Maffei L (2004) Extracellular matrix and visual cortical plasticity: freeing the synapse. Neuron 44:905-908.

Bertrand J, Winton MJ, Rodriguez-Hernandez N, Campenot RB, McKerracher L (2005) Application of Rho antagonist to neuronal cell bodies promotes neurite growth in compartmented cultures and regeneration of retinal ganglion cell axons in the optic nerve sheath of adult rats. J Neurosci 25:1113-1121.

Blesch A, Tuszynski MH (2003) Cellular GDNF delivery promotes growth of motor and dorsal column sensory axons after partial and complete spinal cord transactions and induces remyelination. J Comp Neurol 467:403-417.

Bradbury EJ, Moon LD, Popat RJ, King VR, Bennett GS, Patel PN, Fawcett JW, McMahon SB (2002) Chondroitinase ABC promotes functional recovery after spinal cord injury. Nature 416:636-640.

Brittis PA, Lu Q, Flanagan JG (2002) Axonal protein synthesis provides a mechanism for localized regulation at an intermediate target. Cell 110:223-235.

Bundesen LQ, Scheel TA, Bregman BS, Kromer LF (2003) Ephrin-B2 and EphB2 regulation of astrocyte-meningeal fibroblast interactions in response to spinal cord lesions in adults rats. J Neurosci 23:7789-7800.

Caggiano AO, Zimber MP, Ganguly A, Blight AR, Gruskin EA (2005) Chondroitinase $\mathrm{ABC}$ improves locomotion and bladder function following contusion injury of the rat spinal cord. J Neurotrauma 22:226-239.

Cai D, Shen Y, DeBellard M, Tang S, Filbin MT (1999) Prior exposure to neurotrophins blocks inhibition of axonal regeneration by MAG and myelin via a cAMP-dependent mechanism. Neuron 22:89-101.

Cai D, Qiu J, Cao ZX, McAtee M, Bregman BS, Filbin MT (2001) Neuronal cyclic AMP controls the developmental loss in ability of axons to regenerate. J Neurosci 21:4731-4739.

Chau CH, Shum DKY, Li H, Pei J, Lui YY, Wirthlin L, Chan YS, Xu XM (2003) Chondroitinase ABC enhances axonal regrowth through Schwann cell-seeded guidance channels after spinal cord injury. FASEB J 17:U302-U325.

Chong MS, Woolf CJ, Andrews P, Turmaine M, Schreyer DJ, Anderson PN (1994) The down regulation of GAP-43 is not responsible for the failure of regeneration in freeze-killed nerve grafts in the rat. Exp Neurol 129:311-320.

Christopherson KS, Ullian EM, Stokes C, Maloney C, Hell JW, Agar A, Lawler L, Mosher DF, Bornstein P, Barres BA (2005) Thrombospondins are astrocyte-secreted proteins that promote CNS synaptogenesis. Cell 120:421-433.

Condic ML (2001) Adult neuronal regeneration induced by transgenic integrin expression. J Neurosci 21:4782-4788.

Davies SJ, Fitch MT, Memberg SP, Hall AK, Raisman G, Silver J (1997) Regeneration of adult axons in white matter tracts of the central nervous system. Nature 390:680-683.

Davies SJ, Goucher DR, Doller C, Silver J (1999) Robust regeneration of adult sensory axons in the degenerating white matter of the adult spinal cord. J Neurosci 19:5810-5822.

Ekstrom PA, Mayer U, Panjwani A, Pountney D, Pizzey J, Tonge DA (2003) Involvement of alpha7betal integrin in the conditioning-lesion effect on sensory axon regeneration. Mol Cell Neurosci 22:383-395.

Filbin MT (2003) Myelin-associated inhibitors of axonal regeneration in the adult mammalian CNS. Nat Rev Neurosci 4:703-713.

Fischer D, He Z, Benowitz LI (2004a) Counteracting the Nogo receptor enhances optic nerve regeneration if retinal ganglion cells are in an active growth state. J Neurosci 24:1646-1651.

Fischer D, Petkova V, Thanos S, Benowitz L (2004b) Switching mature retinal ganglion cells to a robust growth state in vivo: gene expression and synergy with RhoA inactivation. J Neurosci 24:8726-8740.

Fitch MT, Doller C, Combs CK, Landreth GE, Silver J (1999) Cellular and molecular mechanisms of glial scarring and progressive cavitation: in vivo and in vitro analysis of inflammation induced secondary injury after CNS trauma. J Neurosci 19:8182-8198.

Fouad K, Schnell L, Bunge MG, Schwab ME, Liebscher T, Pearse DD (2005) Combining Schwann cell bridges and olfactory-ensheathing glia grafts with chondroitinase promotes locomotor recovery after complete transection of the spinal cord. J Neurosci 25:1169-1178.

Fournier AE, Takizawa BT, Strittmatter SM (2003) Rho kinase inhibition enhances axonal regeneration in the injured CNS. J Neurosci 23:1416-1423.

Gao Y, Nikulina E, Mellado W, Filbin MT (2003) Neurotrophins elevate
cAMP to reach a threshold required to overcome inhibition by MAG through extracellular signal-regulated kinase-dependent inhibition of phosphodiesterase. J Neurosci 23:11770-11777.

Goldberg JL, Klassen MP, Hua Y, Barres BA (2002) Amacrine-signaled loss of intrinsic axon growth ability by retinal ganglion cells. Science 296:1860-1864.

Golding J, Shewan D, Cohen J (1997) Maturation of the mammalian dorsal root entry zone-from entry to no entry. Trends Neurosci 20:303-308.

Golding JP, Bird C, McMahon S, Cohen J (1999) Behav of DRG sensory neurites at the intact and injured adult rat dorsal root entry zone: postnatal neurites become paralyzed, whilst injury improves the growth of embryonic neurites. Glia 26:309-323.

Goldshmit Y, Galea MP, Wise G, Bartlett PF, Turnley AM (2004) Axonal regeneration and lack of astrocytic gliosis in Eph A4-deficient mice. J Neurosci 24:10064-10073.

Grimpe B, Silver J (2004) A novel DNA enzyme reduces glycosaminoglycan chains in the glial scar and allows microtransplanted dorsal root ganglia axons to regenerate beyond lesions in the spinal cord. J Neurosci 24:1393-1397.

Grimpe B, Dong S, Doller C, Temple K, Malouf AT, Silver J (2002) The critical role of basement membrane-independent laminin $\gamma 1$ chain during axon regeneration in the CNS. J Neurosci 22:3144-3160.

Grimpe B, Pressman Y, Lupa MD, Horn KP, Bunge MB, Silver J (2005) The role of proteoglycans in Schwann cell/astrocyte interactions and in regeneration failure at PNS/CNS interfaces. Mol Cell Neurosci 28:18-29.

Han PJ, Shukla S, Subramanian PS, Hoffman PN (2004) Cyclic AMP elevates tubulin expression without increasing intrinsic axon growth capacity. Exp Neurol 189:293-302.

Harvey AR, Plant GW (1995) Schwann cells and fetal tectal tissue cografted to the midbrain of newborn rats: fate of Schwann cells and their influence of host retinal innervation of grafts. Exp Neurol 134:179-191.

Irvins JK, Parry MK, Long DA (2004) A novel cAMP-dependent pathway activates integrin function in retinal neurons. J Neurosci 24:1212-1216.

Jin Y, Fischer I, Tessler A, Houle JD (2002) Transplants of fibroblasts genetically modified to express BDNF promote axonal regeneration from supraspinal neurons following chronic spinal cord injury. Exp Neurol 177:265-275.

Jones LL, Margolis RU, Tuszynski MH (2003) The chondroitin sulfate proteoglycans neurocan, brevican, phosphacan, and versican are differentially regulated following spinal cord injury. Exp Neurol 182:399-411.

Kantor B, Chivatakarn O, Peer KL, Oster SF, Inatani M, Hansen MJ, Flanagan JH, Yamaguchi Y, Sretavan DW, Giger RJ, Kolodkin AL (2004) Semaphorin $5 \mathrm{~A}$ is a bifunctional axon guidance cue regulated by heparin and chondroitin sulfate proteoglycans. Neuron 44:961-975.

Kerschensteiner M, Schwab ME, Lichtman JW, Misgeld T (2005) In vivo imaging of axonal degeneration and regeneration in the injured spinal cord. Nat Med 11:572-577.

Kliot M, Smith GM, Siegal JD, Silver J (1990) Astrocyte-polymer implants promote regeneration of dorsal root fibers into the adult mammalian spinal cord. Exp Neurol 109:57-69.

Lander C, Zhang H, Hockfield S (1998) Neurons produce a neuronal cellsurface-associated chondroitin sulfate proteoglycan. J Neurosci $18: 174-183$.

Leon S, Yin Y, Nguyen J, Irwin N, Benowitz LI (2000) Lens injury stimulates axon regeneration in the mature rat optic nerve. J Neurosci 20:4615-4626.

Lin JH, Yahg J, Liu S, Takano T, Wang X, Gao O, Willecke K, Nedergaard M (2003) Connexin mediates gap junction-independent resistance to cellular injury. J Neurosci 23:430-441.

Lu P, Yang H, Jones LL, Filbin MT, Tuszynski MH (2004) Combinatorial therapy with neurotrophins and cAMP promotes axonal regeneration beyond sites of spinal cord injury. J Neurosci 24:6402-6409.

Lu X, Richardson PM (1991) Inflammation near the nerve cell body enhances axonal regeneration. J Neurosci 11:972-978.

McKeon RJ, Hoke A, Silver J (1995) Injury-induced proteoglycans inhibit the potential for laminin-mediated axon growth on astrocytic scars. Exp Neurol 136:32-43.

McPhail LT, Plunet WT, Das P, Ramer MS (2005) The astrocytic barrier to axonal regeneration at the dorsal root entry zone is induced by rhizotomy. Eur J Neurosci 21:267-270.

McQuarrie IG, Grafstein B (1973) Axon outgrowth enhanced by a previous nerve injury. Arch Neurol 29:445-453. 
Medini P, Pizzorusso T, Berardi N, Ratto G, Maffei L (2004) Recovery from early monocular deprivation in adult rats treated with chondroitinase ABC. Soc Neurosci Abstr 30:613.18.

Miyata S, Akagi A, Hayashi N, Watanabe K, Oohira A (2004) Activitydependent regulation of a chondroitin sulfate proteoglycan 6B4 phosphacan/RPTPbeta in the hypothalamic supraoptic nucleus. Brain Res 1017:163-171.

Moon LD, Asher RA, Rhodes KE, Fawcett JW (2001) Regeneration of CNS axons back to their target following treatment of adult rat brain with chondroitinase ABC. Nat Neurosci 4:465-466.

Neumann S, WoolfCJ (1999) Regeneration of dorsal column fibers into and beyond the lesion site following adult spinal cord injury. Neuron 23:83-89.

Neumann S, Bradke F, Tesssier-Lavigne M, Basbaum AI (2002) Regeneration of sensory axons within the injured spinal cord induced by intraganglionic cAMP elevation. Neuron 34:885-893.

Nikulina E, Tidwell JL, Dai HN, Bregman BS, Filbin MT (2004) The phosphodiesterase inhibitor rolipram delivered after a spinal cord lesion promotes axonal regeneration and functional recovery. Proc Natl Acad Sci USA 101:8786-8790.

Oudega M, Hagg T (1999) Neurotrophins promote regeneration of sensory axons in the adult rat spinal cord. Brain Res 818:431-438.

Pasterkamp RJ, Giger RJ, Ruitenberg MJ, Holtmaat AJG, DeWit J, DeWinter F, Verhaagen J (1999) Expression of the gene encoding the chemorepellent semaphorin III Is induced in the fibroblast component of neural scar tissue formed following injuries of adult but not neonatal CNS. Mol Cell Neurosci 13:143-166.

Pearse DD, Pereira FC, Marcillo AE, Bates ML, Berrocal YA, Filbin MT, Bunge MB (2004) cAMP and Schwann cells promote axonal growth and functional recovery after spinal cord injury. Nat Med 10:610-616.

Peng HB, Yang JF, Dai Z, Lee CW, Hung HW, Feng ZH, Ko CP (2003) Differential effects of neurotrophins and Schwann cell-derived signals on neuronal survival/growth and synaptogenesis. J Neurosci 23:5050-5060.

Pindzola RR, Doller C, Silver J (1990) Putative inhibitory extracellular matrix molecules at the dorsal root entry zone of the spinal cord during development and after root and sciatic nerve lesions. Dev Biol 156:34-48.

Qiu J, Cai D, Dai H, McAtee M, Hoffman PN, Bregman B, Filbin MT (2002) Spinal axon regeneration induced by elevation of cyclic AMP. Neuron 34:895-903.

Qiu J, Cafferty WB, McMahon SB, Thompson SW (2005) Conditioning injury-induced spinal axon regeneration requires signal transducer and activator of transcription 3 activation. J Neurosci 25:1645-1653.

Ramer MS, Bishop T, Dockery P, Mobarak MS, O’Leary D, Fraher JP, Priestly JV, McMahon SB (2002) Neurotrophin-3 mediated regeneration and recovery of proprioception following dorsal rhizotomy. Mol Cell Neurosci 19:239-249.

Ramón y Cajal (1928) Degeneration and regeneration of the nervous system (May RM, translator). London: Oxford UP.

Richardson PM, Issa VM (1984) Peripheral injury enhances central regeneration of primary sensory neurons. Nature 309:791-793.

Romero MI, Rangappa N, Li L, Lightfoot E, Garry MG, Smith GM (2000) Extensive sprouting of sensory afferents and hyperalgesia induced by conditional expression of nerve growth factor in the adult spinal cord. J Neurosci 20:4435-4445.

Romero MI, Rangappa N, Garry MG, Smith GM (2001) Functional regeneration of chronically injured sensory afferents into adult spinal cord after neurotrophin gene therapy. J Neurosci 21:8408-8416.

Schnell L, Schwab ME (1993) Sprouting and regeneration of lesioned corticospinal tract fibers in the adult rat spinal cord. Eur J Neurosci 5:1156-1171.
Schwab ME (2004) Nogo and axon regeneration. Curr Opin Neurobiol $14: 118-124$.

Silver J, Miller JH (2004) Regeneration beyond the glial scar. Nat Rev Neurosci 5:146-156.

Sivasankaran R, Pei J, Wang KC, Zhang YP, Shields CB, Xu XM, He Z (2004) PKC inhibitory effects of myelin and chondroitin sulfate proteoglycans on axonal regeneration. Nat Neurosci 7:261-268.

Skene JH, Jacobson RD, Snipes GJ, McGuire CB, Norden JJ, Freeman JA (1986) A protein induced during nerve growth (GAP-43) is a major component of growth-cone membranes. Science 233:783-786.

Snow DM, Lemmon V, Carrino DA, Caplan AI, Silver J (1990) Sulfated proteoglycans in astroglial barriers inhibit neurite outgrowth in vitro. Exp Neurol 109:111-130.

Song H, Ming G, He G, Lehmann M, McKerracher L, Tessier-Lavigne M, Poo M (1998) Conversion of neuronal growth cone response from repulsion to attraction by cyclic nucleotides. Science 281:1515-1518.

Steward O, Schuman EM (2003) Compartmentalized synthesis and degradation of proteins in neurons. Neuron 40:347-359.

Thompson FJ, Reier PJ, Lucas CC, Parmer R (1992) Altered patterns of reflex excitability subsequent to contusion in jury of the rat spinal cord. J Neurophysiol 68:1473-1486.

Tom VJ, Steinmetz MP, Miller JH, Doller CM, Silver J (2004a) Studies on the development and behavior of the dystrophic growth cone, the hallmark of regeneration failure, in an in vitro model of the glial scar and after spinal cord injury. J Neurosci 24:6531-6539.

Tom VJ, Doller CM, Malouf AT, Silver J (2004b) Astrocyte-associated fibronectin is critical for axonal regeneration in adult white matter. J Neurosci 24:9282-9290.

Tropea D, Caleo M, Maffei L (2003) Synergistic effects of brain-derived neurotrophic factor and chondroitinase $\mathrm{ABC}$ on retinal fiber sprouting after denervation of the superior colliculus in adult rats. J Neurosci 23:7034-7044.

Tuszynski MH (1999) Neurotrophic factors, in CNS regeneration: basic science and clinical advances (Tuszynski M, Kordower J, eds), pp 109-158. San Diego: Academic.

Ullian EM, Christopherson KS, Barres BA (2004) Role for glia in synaptogenesis. Glia 47:209-216.

Vaudano E, Campbell G, Anderson PN, Davies AP, Woolhead C, Schreyer DJ, Lieberman AR (1995) The effects of a lesion or a peripheral nerve graft on GAP-43 upregulation in the adult rat brain: an in situ hybridization and immunocytochemical study. J Neurosci 15:3594-3611.

Verma P, Chierzi S, Codd AM, Campbell DS, Meyer RL, Holt CE, Fawcett JW (2005) Axonal protein synthesis and degradation are necessary for efficient growth cone regeneration. J Neurosci 25:331-342.

Wang KC, Koprivica V, Kim JA, Sivasankaran R, Guo Y, Neve RL, He ZG (2002) Oligodendrocyte-myelin glycoprotein is a Nogo receptor ligand that inhibits neurite outgrowth. Nature 417:941-944.

Wong J, Oblinger MM (1990) A comparison of peripheral and central axotomy effects on neurofilament and tubulin gene expression in rat dorsal root ganglion. J Neurosci 10:2215-2222.

Yin Y, Cui Q, Irwin N, Fischer D, Harvey AR, Benowitz LI (2003) Macrophage-derived factors stimulate optic nerve regeneration. J Neurosci 23:2284-2293.

Yin Y, Li Y, Thomas T, Henzl M, Langer R, Benowitz LI (2004) A novel macrophage-derived factor stimulates axon regeneration in the mature rat optic nerve. Soc Neurosci Abstr 30:495.14.

Zheng JQ, Kelly TK, Chang B, Ryazantsev S, Rajasekaran AK, Martin KC, Twiss JL (2001) A functional role for intra-axonal protein synthesis during axonal regeneration from adult sensory neurons. J Neurosci 21:92919303. 